\title{
OS SINOS DA AGONIA, DE AUTRAN DOURADO: TRAGÉDIA CLÁSSICA E ROMANCE PÓS-MODERNO
}

\author{
Marisa Corrêa Silva e Vicente Soares de Oliveira \\ Universidade Federal de Maringá
}

$\mathrm{O}$

romance de Autran Dourado intitulado Os sinos da agonia conta a história de uma rica família de proprietários de terras, os Galvão, na Minas Gerais do século XVIII. A ação se passa em meados de 1788; portanto, algum tempo antes da Conjuração Mineira. A narrativa é dividida em quatro jornadas. $\mathrm{O}$ foco da narrativa é, na primeira parte do texto, centrado na figura de Januário, mameluco e bastardo, filho de outro proprietário de terras. Essa parte conta a paixão obsessiva de Januário por Malvina, esposa do chefe da família Galvão, e a fuga do rapaz após assassinar o marido dela. Na segunda parte, o foco é centrado inicialmente em João Diogo Galvão e seu filho Gaspar; depois, em Malvina. Essa parte narra o casamento de Malvina com João Diogo, feito por interesse; os antecedentes das duas famílias; o amor de Malvina pelo enteado, Gaspar; e as maquinações da moça para persuadir Januário a cometer o crime. Na terceira o foco volta a se aproximar de Gaspar, recontando os meses passados enquanto João Diogo era vivo, o enamoramento do enteado pela madrasta, sua recusa em agir de forma vil, seu drama íntimo ao perceber que Malvina o desejava com paixão, sua resolução de se afastar da moça após a morte do pai. Na quarta e última parte, o foco segue inicialmente Malvina, em seu desespero e ciúme; depois, Gaspar, acompanhando a última intriga da madrasta, que comete suicídio e acusa, numa carta ao CapitãoGeneral, a si própria e ao enteado pela morte do marido; finalmente, Isidoro, escravo de Januário, que acompanha seu amo na volta a Vila Rica; no final da história, o foco volta a fechar em Januário, em seus últimos momentos, morto num confronto com a polícia. 
Maria Lúcia Lepecki já apontou as relações desse romance com o mito de Fedra (LEPECKI, 1976). Sua abordagem, porém foi limitada, apontando as homologias de certos personagens com as Parcas, Tirésias, Fedra e Hipólito. $\mathrm{Na}$ verdade, todas as personagens pertencentes ao núcleo que chamaremos “aristocrático" (por corresponder ao da elite possível no Brasil-colônia, fidalgos e filhos de homens rudes enriquecidos) da narrativa são baseadas no mito de Fedra e seus antecedentes. Demonstrar isso, e aventar uma hipótese coerente com o papel de Januário na narrativa, é o objetivo deste estudo.

Iniciaremos com um breve relato da história das família:

Valentim, pai de João Diogo, era um homem rico e voluntarioso. Morre do coração ao receber a falsa notícia da morte do filho, que herda seus bens. Diogo se casa e tem um único filho, Gaspar, descrito como solitário, casto e amante da caça. Viúvo de Ana Jacinta há muitos anos, Diogo resolve se casar de novo e passa a cortejar Mariana, filha de uma família de Taubaté, gente da nobreza vicentina "sem mácula" (ao contrário de Diogo, cuja riqueza é herdada do pai, geralista de origem obscura), empobrecida mas decidida a restaurar seu antigo patrimônio. Os pais da escolhida, Dom João Quebedo Dias Bueno e D. Vicentina, tem mais dois filhos: Donguinho, insano, de comportamento animalesco, fruto de uma relação extraconjugal da mãe, vive preso num quarto; e Malvina, a caçula, linda e sem escrúpulos. Malvina resolve seduzir Diogo e este se encanta com ela, pedindo-a em casamento, para grande sofrimento da irmã mais velha, que vai para o convento.

Após o casamento, Diogo leva a esposa para Vila Rica, onde a vida corre tranqüila, até que Gaspar e Malvina se conhecem. Ambos se apaixonam: ela, loucamente; ele, com tristeza e culpa. Gaspar deseja proceder de forma correta e se afasta da madrasta, tratando-a com frieza. Esta concebe o plano que levará Diogo à morte: seduz o pobre mameluco Januário e o convence a matar o marido. A mucama Inácia, confidente de Malvina, facilita o adultério com Januário e serve de leva-e-traz à ama. Morto Diogo, Januário tem a fuga facilitada pelo pai, que o faz acompanhar pelo escravo Isidoro. O rapaz é enforcado em efígie, o que corresponde, simbolicamente, à sua morte oficial. Livre de Januário, Malvina revela seu amor ao enteado, que a repudia, ficando noivo de Ana, jovem casta e de hábitos irrepreensíveis. Cheia de ódio, Malvina se envenena e escreve à polícia, acusando o enteado e a si própria pela morte de João Diogo. Ele é enforcado. Januário, teoricamente inocentado pela carta de Malvina, 
é morto num confronto com a polícia. Isidoro foge e diz que vai fundar um grande quilombo, e nunca mais vai falar "língua de branco".

O próprio Autran Dourado explica que boa parte da diegese foi originada no mito de Fedra. Observemos, a seguir, as correspondências entre as personagens oriundas das classes privilegiadas e as personagens do mito:

Valentim e Egeu: Egeu era rei de Atenas, pai de Teseu. Quando o filho vai a Creta com a missão de enfrentar e matar o Minotauro, ele pede ao rapaz que coloque velas coloridas em seu barco, caso retorne vitorioso. $\mathrm{O}$ moço esquece o pedido do pai. Egeu, do alto de um promontório, ao ver o barco do filho retornar com as velas comuns, julga que o rapaz morreu e se atira ao mar, perecendo. Valentim, como já dissemos, também morre ao receber a notícia errônea da morte de Diogo.

Diogo e Teseu: Este era casado com Hipólita, rainha das amazonas, e tinha um filho, Hipólito. Ela morre e Teseu, em sua viagem a Creta, conhece Ariadne, filha do rei, e resolve se casar com ela. Como Teseu, Diogo fora um grande sedutor em sua juventude e idade madura; após a união com Fedra/Malvina, porém, o antigo mulherengo modifica sua conduta. Ambos tem uma relação de respeito mútuo com o filho casto. As semelhanças diminuem a partir daí: Teseu retorna de viagem e Fedra, tento revelado seu amor a Hipólito, acusa o rapaz de atentar contra sua honra. Teseu pede a Netuno que mate o rapaz, no que é prontamente atendido.

No romance, Malvina obtém do amante rústico e ingênuo a morte do marido; para que a similitude entre sua trajetória e a de Fedra permaneça, é preciso que outra personagem assuma a posição de autoridade máxima, capaz de julgar e condenar Gaspar. O Capitão-General é quem vai assumir tal papel; é a ele que ela endereça a carta acusatória. Por isso a lógica, na estrutura da ação, da côrte que o alto oficial faz à moça, e a passagem no capítulo IV, onde Malvina, viúva, lamenta ter-se entregue, levianamente, a ele, numa tentativa desesperada de provocar ciúmes em Gaspar (p. 187). Também deixa de ser apenas casual a frase que o Capitão-General diz a Gaspar, no enterro de Diogo: "Vamos nos dar bem, meu filho (...). Permitame tratá-lo assim, pela grande estima que tinha por seu pai.”(p. 143). O oficial ocupa o papel do marido morto, assumindo as tarefas de Teseu.

Mariana e Ariadne: A filha mais velha de Minos, rei de Creta, se apaixona por Teseu e foge com ele, levando consigo sua irmã, Fedra. No 
caminho para Atenas, Teseu se apaixona por Fedra e abandona Ariadne na ilha de Naxos, causando-lhe intenso sofrimento. Segundo algumas tradições, Ariadne morre de tristeza; segundo outras, deixa-se consolar por Dionisos.

Dom Quebedo, D. Vicentina, Donguinho, Minos, Pasífae e o Minotauro: Minos, rei de Creta, fora traído pela rainha, Pasífae, que se apaixonou por um touro sagrado e engravidou do animal, dando à luz o Minotauro, monstro metade homem, metade touro. O rei manda construir o labirinto de Creta e prende o monstro lá dentro.

Malvina e Fedra, Inácia e a Ama: Fedra, filha de Minos e Pasífae, irmã mais jovem de Ariadne, foge com esta e com Teseu após o encontro do herói com o Minotauro. Ao chegar em Atenas, Teseu se casa com Fedra e ambos vão reinar na cidade. Anos depois, Fedra se apaixona pelo enteado. $\mathrm{Na}$ tragédia de Eurípides, ela acaba por confessar seu amor proibido à ama; a serva revela o segredo a Hipólito, que se horroriza e trata a madrasta com rudeza. Fedra se enforca e deixa uma carta ao marido, acusando Hipólito de havê-la seduzido. Inácia possui, em comum com a ama, uma dedicação total à senhora.

Gaspar e Hipólito: Ambos eram castos, dedicados à caça, sentiam-se pouco à vontade frente às mulheres. Hipólito tem essa castidade explicada por sua dedicação total à deusa Ártemis (a Diana Caçadora dos romanos), desprezando Afrodite, a quem se torna antipático. Falsamente acusado por Fedra, ele é exilado. Ao iniciar sua viagem, seus cavalos são assustados por um monstro saído do mar a mando de Netuno, protetor de Teseu. O jovem é arrastado e ferido de morte no acidente. Gaspar é casto pelo trauma provocado pela morte da mãe. Corre o boato de que sua castidade seria resultado de uma promessa à Virgem Maria, e ele não nega.

Outro dado curioso, mais sutil, é a coincidência de prenomes entre João Quebedo/ João Diogo e Ana Jacinta/Ana. Pai e marido de Malvina, mãe e noiva de Gaspar. Tais coincidências podem perfeitamente ser lidas, à luz do mito, como referência à perpetuação das maldições, dos erros, dentro da família; e uma metáfora da atração incestuosa - o amor entre madrasta e enteado - que, embora não se concretize fisicamente, existe no romance. Uma leitura freudiana indicaria o desejo de Malvina e Gaspar de escolher parceiros de forma edípica: João Diogo seria o resgate do João Quebedo rico da infância de Malvina, para ela perdido na pobreza; e Ana, recatada e de bom coração, reproduziria as virtudes características da 
morta Ana Jacinta. A coincidência dos prenomes pode ser lida como um indicativo a mais de que essas uniões estavam fadadas ao fracasso. A família amaldiçoada pela endogamia, ainda que apenas simbólica, não tinha salvação. O casamento de Malvina e Diogo não apaziguaria a vileza da moça; o amor de Ana não resgata o destino de Gaspar.

Além dessas similitudes, também observamos alguma influência da releitura do mito feita por Jean Racine, dramaturgo francês do século XVIII. Racine, ao reelaborar o tema na tragédia Fedra, retirou a intervenção do deus ex machina e alterou a ordem das mortes de Fedra e Hipólito, conferindo maior verossimilhança ao todo. Em Eurípides, Hipólito permanece durante toda a tragédia um campeão da virtude; a deusa Ártemis desce do Olimpo, a fim de consolar o rapaz agonizante e revelar a verdade. Já em Fedra, a esposa acusa o enteado; Teseu pede vingança a Netuno; é atendido. Ao receber a notícia da morte do enteado, Fedra toma veneno e, agonizante, confessa sua culpa a Teseu.

Em Os sinos da agonia, a ordem das mortes de Malvina e Gaspar é mantida tal como em Eurípides. Tampouco acontece uma "revelação" da verdade para as outras personagens. O romance não tem a preocupação de fazer o equilíbrio do mundo retornar, seja pela intervenção do Olimpo, seja através da confissão. Basta a ele que o leitor conheça a verdade. Afinal, ele tenta retratar um mundo em grave desequilíbrio: a crise econômica provocada pelo progressivo esgotamento das minas e aluviões; a ameaça da derrama, que desaguaria na Inconfidência mineira; o artificialismo das elites, tentando reproduzir nas condições brasileiras o estilo de vida das capitais européias; a escravatura, que deveria repugnar os espíritos sensíveis mas que, sendo fonte de riqueza, era encarada com naturalidade; enfim, as mazelas incuráveis de uma sociedade incapaz de enxergar o homem que a constituía, mas que tentava se representar como européia e cosmopolita, tudo isso está magnificamente explorado no texto de Autran Dourado.

A influência de Racine, que mencionamos anteriormente, está em outros pontos. Para não provocar suspeitas sobre a masculinidade de Hipólito, já que o culto de Afrodite dificilmente seria aceito como explicação suficiente pelo público de Racine, ele cria uma amante para o rapaz: Aricia, filha de Palas, inimigo de Teseu. $\mathrm{O}$ amor proibido dos dois jovens provoca intenso ciúme, humilhação e sofrimento em Fedra. Aricia era casta, também, por 
imposição de Teseu, que condenara toda a família da moça à morte, poupando a jovem, sob condição de que ela jamais se casasse ou tivesse filhos. Em Ana, temos, portanto, uma semelhança com Arícia, a jovem pura e de hábitos irrepreensíveis, contraponto de Malvina/Fedra.

Também Racine explora e aumenta a relação entre Fedra e a Ama. A segunda ganha um nome próprio, Enone; é dedicadíssima à rainha e se atira ao mar após ser duramente recriminada por Fedra, que a acusa de tê-la precipitado na desgraça. Em Autran Dourado, a dedicação e o amor de Inácia pela sua sinhazinha também são reiterados, especialmente na quarta jornada, quando Malvina está mergulhada em desespero e a mucama faz de tudo para consolar a jovem: adivinha seus pensamentos: "Nhazinha pensa que eu não gosto mais dela? disse a preta parece adivinhando" (p. 176); mente que Gaspar prometera visitar a madrasta (p. 180); e sofre um choque fortíssimo ao receber a notícia do suicídio de Malvina: "Inácia deu um grito, caiu de joelhos no chão. Entre baba, lágrimas e solu $\div$ os, ela chorava e se lastimava numa mistura de ioruba e língua do reino" (p. 205). Embora a relação de ambas passasse pelos interesses da mucama, que gozava do conforto e dos poderes adquiridos pela cumplicidade com a sinhá, essa série de atitudes indica uma afeição verdadeira entre senhora e escrava.

Algumas das dissemelhanças nas tramas do romance e da tragédia são bastante evidentes; elas obedecem a uma necessidade interna de verossimilhança. Por exemplo, a morte de Valentim ocorre anos antes do casamento de Diogo e Malvina. A de Egeu acontece no momento em que o casal Teseu-Fedra vai chegando ao porto de Atenas. Teseu era apenas um entre os muitos filhos de Egeu, antipatizado pela madrasta, Medéia. Seu status, ao ir para Creta, é o de um aventureiro, o que explica a necessidade da fuga das princesas: um rei, ou o herdeiro reconhecido do trono de Atenas possivelmente pleitearia a mão da princesa de Creta sem subterfúgios. $O$ fato é que Teseu precisou lutar para assegurar o trono para si próprio. Já João Diogo, ao cortejar Mariana e Malvina, era reconhecido como "potentado" pelo futuro sogro. O casamento do velho com qualquer uma das moças aparecia como a solução definitiva para as aflições financeiras da família. Por isso é que os fidalgos vicentinos fazem vista grossa às origens evidentemente sem nobreza do noivo.

Tampouco Diogo mata Donguinho; a eliminação do Minotauro, um dos feitos que consagram Teseu como herói, não teria sentido se transposta 
para a ação do romance. Donguinho, louco, mas humano, merece piedade. O tema da monstruosidade na família, típico do mito grego, é, contudo, mantido: Malvina, ao devanear sobre o desejo que sentia por Gaspar, sentese fundida com Donguinho, animalizada, seus instintos dominando a razão: "Era Donguinho redivivo nela vindo amorosamente se fundir" (p. 117).

A morte de Diogo é outro momento distinto. Teseu, numa de suas aventuras, é falsamente dado como morto, o que permite a Fedra alimentar suas ilusões amorosas. Diogo é morto de fato, precipitando a trama. O romancista poderia ter optado por manter a falsa notícia de morte, mas a inclusão de Januário na trama e, mais ainda, a opção pela monstrificação de Malvina, tornam o assassinato do velho geralista mais lógico. Para o leitor contemporâneo, a paixão de Malvina pode ser embaraçosa, mas não é criminosa; lastimável, não monstruosa. De certa forma, ela parece inclusive previsível: casada aos vinte anos com um homem muito mais velho, o convívio com Gaspar, belo e sensível, seria uma tentação grande demais. Portanto, a reconstrução do caráter monstruoso da moça precisa conter elementos mais persuasivos para o leitor contemporâneo. O caráter vil da jovem se revela na frieza com que Malvina seduz o mameluco, convence-o a matar o marido, dizendo que a morte deve ser de choque, ou sufocando-o com o travesseiro, para que pareça morte natural; ela, porém, já planejara um duelo sangrento, sabendo que Diogo dormia ao lado de uma arma; ao fazer o amante penetrar no quarto do marido, põe na mão dele um punhal. A luta é inevitável e a morte de Diogo, homicídio evidente. Januário tem de fugir e ela lhe dá um cofre de jóias, para poder depois acusá-lo de latrocínio e ficar livre de ambos, marido e amante.

O mameluco, instrumento do plano monstruoso, é descrito o tempo todo como valente, rude, ousado. Sua côrte a Malvina é descarada, ele não teme Diogo nem Gaspar. Por ele, teria fugido com a amante. Ela é que tece um discurso duplo, destinado a torná-lo instrumento dócil: ora diz que não suportaria viver na pobreza, tendo sido criada no luxo, ora diz temer a vingança implacável do marido no caso da fuga. Consciente de sua posição de "filho das ervas", Januário dá razão à amante e se submete à vontade desta. Ao entrar no quarto de Diogo e ver a arma ao lado do homem deitado, não tem tempo de pensar e age premido pelas circunstâncias. Somente muito tempo depois, ao regressar a Vila Rica, é que compreende a extensão total do logro em que caíra. 
Dentro do universo clássico, uma personagem como Januário não teria muita importância: centrada no "homem superior", filho de reis ou de um deus, a narrativa do tipo trágico ou épico não focaliza o homem das classes inferiores. Pode apresentá-lo cumprindo ordens, trazendo notícias, ou ainda, como no caso da ama de Fedra em Hipólito, praticando ações consideradas "desonrosas" no lugar de seus senhores. Januário é a pedra de toque desse romance, o elemento que transforma tudo. Não apenas pobre e mestiço, mas bastardo; e bastardo de um homem rico, o que enfatiza a responsabilidade das classes superiores em relação aos menos favorecidos, o mameluco introduz a focalização no romance, como podemos ver no capítulo I. Seu conhecimento parcial dos fatos, sua paixão por Malvina, são as primeiras impressões que o leitor tem do universo textual.

Desta maneira, Autran Dourado faz com que o leitor inicie o romance não apenas in media res, mas através do ponto de vista do homem comum. Se a opção fosse iniciar o livro pela segunda parte, o parentesco da estrutura textual com a tragédia ficaria como primeira impressão, já que os paralelismos na trajetória das personagens e em seu status de membros de uma casta superior são bastante visíveis. Iniciar (e encerrar) a narrativa através de Januário implica em valorizar o ponto de vista do homem do povo, numa estratégia análoga a de José Saramago em Memorial do convento, onde a intenção do autor em reescrever a história de Portugal num diálogo com as crônicas dos reis que, ao contrário destas, enfatizasse a dignidade e a importância do indivíduo por elas ignorado: o homem e a mulher do povo.

Na segunda parte, o foco muda para as personagens aristocráticas (seja pelo efeito da linhagem, seja pelo efeito da riqueza amealhada); embora o narrador se permita fazer afirmativas bastante cabais sobre os sentimentos das personagens ("Não queria questão com o pai, respeitava-o" - p. 69), ele procura reproduzir as falas e pensamentos destas a maior parte do tempo.

A quarta parte do livro alterna os pontos de vista da primeira e da segunda parte. A focalização muda de Malvina para Gaspar, Isidoro e Januário. Essa focalização alternada acontece, não por acaso, no momento de solução dos conflitos pendentes. Tal solução é final para João Diogo, Gaspar, Malvina e Januário; e aberta, para Isidoro. Os três primeiros são aniquilados pelo jogo promovido por eles próprios, maliciosamente ou não, no sentido de atenderem as próprias paixões. Gaspar não é diferente: sua paixão pela pureza su- 
planta o amor por Malvina, guiando seus atos e precipitando o final. Januário é o homem dividido entre sua posição inferiorizada e seu desejo de obter os valores da cultura branca e aristocrática , metaforizados pela posse de Malvina, cujo corpo se converte em bem material, como fica exemplificado no pensamento do enciumado mameluco: "Agora, Gaspar podia desfrutar o corpo de Malvina, os seus segredos. Se é que já não desfrutava há muito tempo, mesmo antes" (p. 216). Esse desejo de "ascender" às alturas onde Malvina (a quem ele repetidamente se refere como "rainha") e Gaspar se encontravam é a sua perdição. Isidoro, porém, de escravo humilde e supersticioso é quem realiza uma ascensão: passa a falar de igual para igual com o amo Januário, resolve fugir para a liberdade e só falar ioruba, para não ser entendido pelos brancos; renega o mundo e os valores do branco e jura fundar um quilombo maior do que o mitificado Quilombo Grande de Pai Ambrósio.

Podemos concluir, então, que o recurso de fundamentar as personagens do núcleo de elite nos mitos de Teseu e Fedra é muito mais do que um jogo intertextual: ele vem como cerne das ações que fundamentam a narrativa, mas surge complementado e iluminado através da visão do mameluco. É como se o romance desejasse ilustrar a tese de que nenhuma história possui apenas protagonistas "elevados", gente considerada importante, líderes, etc.; mas devesse também, sob pena de ficar incompleta e falsear seu sentido, encontrar o(s) protagonista(s) desprezados, heróis humildes, escondidos entre o populacho, para revelar ao leitor um pathos complementar ao de Gaspar, moldado parte através de uma natureza humana que poderíamos classificar de universal (o desejo do jovem por uma bela mulher), e parte através da manipulação ideológica, via discurso, do indivíduo menos favorecido pelos representantes da elite (o jogo de Malvina, que um homem da mesma condição social que ela poderia reconhecer e evitar).

Portanto, Os sinos da agonia é partícipe de uma das tendências reconhecidas no romance da segunda metade do século XX: a metaficção historiográfica. Ao narrar uma história passada no século XVIII, no período imediatamente anterior ao da Inconfidência - que, aliás, é introduzida na mente do leitor quando o Capitão-General acusa Januário de matar Diogo não por roubo, mas para sinalizar aos seus "companheiros" (inexistentes) o momento de eclodir uma revolta contra Sua Majestade o rei de Portugal Autran Dourado mescla duas tradições distintas: 
a que chamaremos "clássica”, por corresponder aos padrões pré-românticos, praticada nos gêneros ditos "elevados", onde as personagens pertenciam à classe dominante, seu estilo era "elevado", o vocabulário limpo de vulgaridades;

a que chamaremos "romântica", por corresponder à mistura de gêneros, à liberdade que os românticos pregavam, negando a autoridade dos clássicos. A partir desse momento, protagonistas de extração humilde poderiam ter idéias e sentimentos nobres, adquirindo um estatuto de igualdade perante os ricos.

A focalização, ora acompanhando as personagens pertencentes à elite, ora o bastardo Januário e o escravo Isidoro, é o instrumento principal de mescla das duas tradições.

Além disso, o recurso de intertexto com a tragédia clássica confere um escopo mais ambicioso ao romance. É como se a reescritura crítica não se limitasse ao registro histórico da época barroca e árcade, mas a toda a tradição da literatura ocidental desde a Grécia, passando pelas poéticas de Horácio e de Boileau, que pregavam igualmente a pureza de gêneros. Os sinos da agonia, ao reescrever a História, reclama para aquele homem que o século XVIII invisibilizava em sua auto-representação dita "elevada”, relegando-o à esfera do cômico, do picaresco e da sátira, um espaço no registro dessa mesma História, enquanto co-protagonista de seus dramas.

\section{BIBLIOGRAFIA}

DOURADO, Autran. Os sinos da agonia. 3.ed. Rio de Janeiro: Difel, 1977.

EURÍPIDES. Medéia - Hipólito - As Troianas (trad. Mário da G. Kury) 4.ed. Rio de Janeiro: Jorge Zahar, 1999.

HUTCHEON, Linda. Narcissistic narrative: the metafictional paradox. New York: Methuen, 1984.

—. Poética do Pós-modernismo (trad. Ricardo Cruz). Rio de Janeiro: Imago, 1991.

LEPECKI, Maria Lúcia. Autran Dourado: uma leitura mítica. S. Paulo: Edições Quiron MEC, 1976.

OLIVEIRA, Vicente Soares. "Os sinos da agonia: a relação das personagens com a mitologia greco-romana”. Monografia de final de curso de graduação, orientada pela profa. Dra. Marisa Corrêa Silva. UEM, Maringá, 2002.

RACINE, Jean. Phédre, s.d. 